doi: 10.26529/cepsj.592

\title{
David J. Connor, Beth A. Ferri and Subini A. Annamma (Eds.), DisCrit: Disability Studies and Critical Race Theory in Education, Teachers College Press: New York, NY, 2016; 279 pp.: ISBN 978-0-8077-5667-6
}

Reviewed by Josefine WAGNER ${ }^{1}$

At the intersection of disability and migration experience, vulnerable bodies are easily constructed that become subjected to specialised care, harming individuals rather than enabling them to access free, quality, primary, and secondary education. In 2006, the United Nations Convention on the Rights of Persons with Disabilities (UN-CRPD) put forward a social-constructivist understanding of the term 'disability' that focuses on barriers to participation in society, instead of individuals' limitations and the medical gaze on the 'disabled' body. Ratified by the European Union (EU) in 2010, the UN-CRPD has become in-

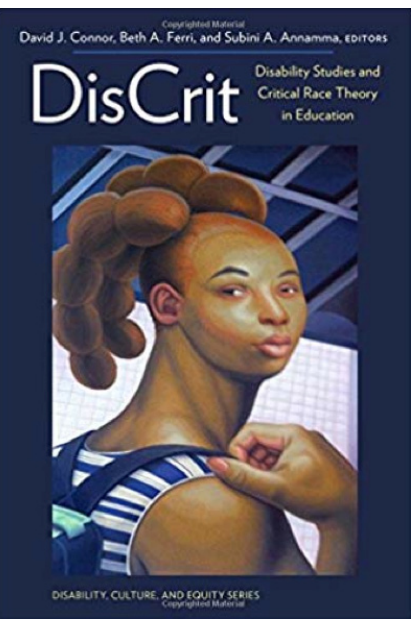
structive to EU Member States, since regular monitoring reports issued by UN committees hold countries accountable for realising acts, such as: 'State parties shall ensure that [...] (b) Persons with disabilities can access an inclusive, quality and free primary and secondary education on an equal basis with others in the communities in which they live; [...]' (2006, article 24.2b, p. 17). Limiting special education and channelling more and more students with disabilities and special needs into mainstream education has led to increased diversity in classrooms, even more so in those countries with considerable migration populations. Alienating as it might seem to some teachers at first, all students have the right to the education that has been available to able-bodied classmates of the dominant cultural group. Boxing students into categories does not foster the bond that creates a community of students. Where there is no relationship between teacher and students as well as among students, and where there is no respect for the unique ways students learn, there will be no progress, neither content-wise or socially.

1 Early Stage Researcher in the European Doctorate in Teacher Education (EDiTE) at the University of Lower Silesia, Poland and the University of Innsbruck, Austria; josefinewagner@yahoo.com. 
With regards to the American research landscape, interdisciplinary approaches champion the way of looking and describing classroom activities to better respond to the many contexts in which teaching and learning take place. In this volume, DisCrit: Disability Studies and Critical Race Theory in Education, Inclusive Education, scholar David J. Connor, special education scholar Subini A. Annamma, and inclusive education and disability studies scholar Beth A. Ferri have joined forces. Through their areas of expertise, they offer a framework that takes both disability and non-whiteness in education into view, focusing on issues of segregation and urban schooling. In the European education research landscape, attempts to bridge the gap between two seemingly different disciplines of special education and inclusive education are rare. Even more unique is the reading of both disciplines with attention to matters of belonging to cultural and ethnic minority groups within European societies. In countries, such as Austria in which more students with Turkish or Bosnian/Croatian /Serbian as their mother tongue attend special schooling than mainstream primary education, the first steps have been made to raise educators' awareness for the construction of disability through language. In federally organised Germany, Berlin has abolished special schools and makes use of a system of nine special needs statuses with which students can be diagnosed. Students with migration experiences rank alarmingly high under the status of 'emotionally and socially challenged', pointing to a more significant issue of social and cultural mediation. Intercultural learning needs to join the conversation between special and inclusive educators as we want to prepare teachers and pedagogical members of staff for classrooms which offer, in an extraordinary way, the wealth of human expression. This is not to say that DisCrit must always be read with a clear multicultural perspective. Also in classrooms in Post-Socialist Central European societies, in which migration may play a minor role, valuable food for thought can be found in this volume since it approaches aspects that are central to teaching children with special needs.

One way of opening a conversation that addresses matters of diversity, ability-wise as well as culturally, in education would be to engage with the framework of DisCrit that Connor, Annamma, and Ferri introduce in their book DisCrit: Disability Studies and Critical Race Theory in Education. The main goal of the volume is to apply the tenets of DisCrit and make it a thick and robust framework to look at practices in education. Each article put forward by a different group of scholars or individuals places itself within the principles of the framework, indicating the relevance that the framework, though somewhat preliminary, offers. The framework builds on seven tenets. In short, these encompass (1) DisCrit questions normalcy by addressing how racism and ableism 
interrelate to create hegemonic notions the normal; (2) DisCrit appreciates an approach of multidimensional identities; (3) DisCrit recognises the social construction of identity categories but highlights the material and psychological consequences that may arise from labels of such categories; (4) DisCrit emphasises the voice of marginalised groups of society in research; (5) DisCrit views the analysis of dis/ability and racism with regard to historical and legal dimensions; (6) DisCrit regards Whiteness and Ability as properties and that benefits for people labelled dis-abled have often been achieved for White, Middle-class members of society; and (7) DisCrit supports resistance (p. 19). The authors discard the terminology of 'disability' and propose instead 'dis/ability' to stress their commitment to ' 1 : Counter the emphasis on having a whole person be represented by what he or she cannot do, rather than what he or she can, and 2: disrupt notions of the fixity and permanency of the concept of disability, seeking rather to analyse the entire context in which a person functions.' (p. 1)

Though not their first joint publication on theorising DisCrit (see, e.g., Annamma, Connor, \& Ferri, 2012), the three scholars highlight the potential for further enriching the framework by inviting colleagues to explore the framework with their own takes. Framed by an introductory article A Truncated Genealogy of DisCrit and the touchstone text Dis/Ability Critical Race Studies (DisCrit): Theorizing at the Intersections of Race and Dis/ability, the volume is divided into six parts: (I) Race, Class, and Ability, (II) Achievement/ Opportunity Gap, (III) Overrepresentation, (IV) School-to-Prison Pipeline, (V) School Reform and (VI) Race, Disability and the Law. Each part is featured in two articles.

In part one, David Gillborn, Nicola Rollock, Carol Vincent, and Stephen J. Ball discuss The Black Middle Classes, Education, Racism, and Dis/ability: An Intersectional Analysis. In 77 interviews with Black middle-class parents, living in England, the authors explore how social class, ability and identities of race (Black Caribbean) most often create situations for students in which they are directed to segregated, third-class education through pseudo-medicalised labels. Furthermore, Alicia A. Broderick, and Zeus Leonardo address 'goodness' as a property that has material implications for students. Very convincingly, the authors argue for 'goodness' as a category that is actively constructed through cultural discourse. Broderick and Zeus invite educators to explore how practices of 'goodness' matter in the construction of student identities and how 'goodness' becomes interlinked with privileges and accesses to services, such as extra lessons, support teachers, and others or the withdrawal of such. With regard to remaining a reflexive practitioner, no matter how diverse or monocultural the classroom maybe, I highly recommend studying this article. 
In the second part, Elizabeth Mendoza, Christina Paguyo, and Kris Gutierrez make use of cultural-historical activity theory (CH/AT) to question common sense and everyday beliefs about cultural groups, ability, and other factors. This way attention can be drawn to White privilege and notions of normalcy. Using the example of IQ testing, the authors deconstruct the legitimacy of intelligence tests as they facilitated discourses and practices of eugenics in the past. Moreover, Kathleen A. King Thorius and Paulo Tan argue in favour of 'educational debt' in place of the narrative of 'achievement gaps.' Whereas achievement gap framings in education invite rather superficial solutions, educational debt takes into view the complexities of injustice resulting from historically grown, economic, socio-political, and moral debt.

In the third part, Elizabeth B. Kozleski and Edward Fergus take up the theme of overrepresentation through the topics of measurement in education and teacher beliefs. Kozleski outlines how big data collection and interpretation by institutions, such as the Office of Civil Rights (OCR) and the National Centre for Education Statistics (NCES) reinforces overrepresentation of minority students in special education. Fergus presents a study in which he combines social reproduction theory and DisCrit to investigate to what extent ideologies, regarding racial constructs, such as deficit thinking, colour-blindness, and other factors matter in teacher self-reports of their own work in the classroom.

The fourth part is dedicated to the analysis of the school-to-prison pipeline. This topic is discussed by authors D. L. Adams and Nirmala Everelles, who focus on 'carceral logics', and Claustina Mahon-Reynolds and Laurence Parker who stress the overrepresentation of students of colour with learning disability among the prison population. As early police contact of minors has strong implications for future involvement with the police, the authors emphasise an intersectional perspective on the overrepresentation of non-White students with dis/abilities in the American prison system. First emphasised as a phenomenon when the report Cellblocks or Classrooms? issued by the Justice Policy Institute (Schiraldi \& Ziedenberg, 2002) highlighted that there were more Black men in prisons than in secondary education, the school-to-prison pipeline remains worthy of critical investigation.

In the fifth part, the policy perspective is put under scrutiny. Sally Tomlinson highlights the DisCrit framework as a theory of justice and draws interesting parallels to John Rawls and his works on social arrangements and the way that educational and economic opportunities are distributed in society. Tomlinson also draws on the historical dimension to highlight how changing notions of justice manifested in legal acts constituted oppression for some and privilege for others along the lines of dis/ability and race. Susan Baglieri 
discusses fruitful angles of critique when reading school reforms with regard to multiculturalism, inclusive education and DisCrit. She analyses the narrative of students 'at risk' coupled with the simplified language of 'urban children', i.e., Black, Brown and poor kids, and 'special needs' in place of complex histories, identities and positions in legal texts of school reforms. As neoliberalism needs to construct schools as disaster zones to employ measurement and progress schemes, Baglieri argues, markers as the above pathologise those children [Black, Brown, poor, dis/abled] that it construes to 'save'. As the language of policy easily passes as 'neutral' and integrates into everyday discourse, this article is highly recommended as it encourages to look behind figures of speech and to question how agenda setting is framed.

The final part engages, on the one hand, with DisCrit as a lens to evaluate a recent court ruling in the case of George Zimmerman who shot unarmed Trayvon Martin, a Black, 17-year-old teenager, because he seemed out of place in the neighbourhood. In one of the most gut-wrenching chapters of the volume, Kathleen M. Collins demonstrates how racism and ableism create identities 'out of place' to justify incarceration, harm, and segregation. In contrast, Zanita E. Fenton shows in detail how slavery worked at dis/abling the Black body physically, psychologically, intellectually and how forced sterilisation functioned as a mutilating instrument for various groups of American society throughout history to prevent, in eugenic fashion, the spread of 'feeblemindedness' or unfavourable life and genes. Fenton argues, though sensitive to hierarchies of suppression, for weakening categories of identities so that alliances become possible allowing for mutual empowerment.

Generally, the volume refers to the Anglo-American context, which allows for creative adaptation and inspiration with regard to the wider European context. This book is truly recommendable for building one's own theoretical base, to receive ideas on methodological design for research purposes, to inspire teacher educators, and to gain food for thought as a practitioner involved in classrooms and school management. Though the language is at times overcomplicated and could be altered for addressing a larger audience that would truly profit from this research in their daily work, I would still recommend it to teachers, paedagogical and management staff at schools. Since teachers more often than not belong to the able-bodied, majority culture of a society, a self-reflexive engagement can truly be spurred by taking the research that this framework has motivated and is at display in DisCrit: Disability Studies and Critical Race Theory in Education to heart. 


\section{References}

Annamma, S. A., Connor, D. J., \& Ferri, B. A. (2016). Touchstone text: Dis/ability critical race studies (DisCrit): Theorizing at the intersections of race and sis/ability. In D. J. Connor, B. A. Ferri, \& S. A. Annamma (Eds.), DisCrit: Disability studies and critical race theory in education (pp. 9-34). New York, NY: Teachers College Press.

Schiraldi, V., \& Ziedenberg, J. (2002). Cellblocks or classrooms? The funding of higher education and corrections and its impact on African American men. Washington, D.C.: Justice Policy Institute. Retrieved from http://www.justicepolicy.org/uploads/justicepolicy/documents/o2-o9_rep_ cellblocksclassrooms_bb-ac.pdf

United Nations. (2006). Convention on the rights of persons with disabilities and optional protocol. Retrieved from http://www.un.org/disabilities/documents/convention/convoptprot-e.pdf 